\title{
NoTe
}

\section{Pancreatic beta cell function in lean and obese Japanese with various degrees of glucose tolerance}

\author{
Mitsuyoshi Takahara $^{1)}$, Naoto Katakami ${ }^{1)}$, Hideaki Kaneto ${ }^{1)}$, Midori Noguchi ${ }^{2)}$ and Iichiro Shimomura ${ }^{1)}$ \\ 1) Department of Metabolic Medicine, Osaka University Graduate School of Medicine, Suita 565-0871, Japan \\ ${ }^{2)}$ Health Support Promotion Section, Environment and Civic Affairs Bureau, Amagasaki City Office, Amagasaki 660-0051, Japan
}

\begin{abstract}
The aim of the current study was to investigate whether obese subjects have different insulin secretory capacity compared to lean subjects with the same glucose tolerance in a Japanese population. We included a total of 1749 Japanese employees who underwent 75-g oral glucose tolerance test (OGTT). The study population was divided into deciles of 120min glucose levels and the indices of insulin secretion and insulin sensitivity in each decile were compared between the subjects with and without obesity (body mass index $\geq 25 \mathrm{~kg} / \mathrm{m}^{2}$ ). The indices used in the current study were Matsuda index, insulinogenic index, and disposition index. Obese subjects had significantly lower values of Matsuda index and significantly higher value of insulinogenic index than non-obese subjects in every decile (all $p<0.05$ ). On the other hand, disposition index was not significantly different between non-obese and obese subjects in any decile of 120-min glucose level (all $p>0.05$ ). Similar findings were observed when the study population was classified by waist circumference. In conclusion, disposition index derived from the data of 75-g OGTT was similarly decreased in obese Japanese subjects compared to non-obese Japanese subjects with the same post-load glucose levels. Future studies will be needed to confirm whether the development of glucose intolerance in obese Japanese subjects is accompanied by the same degree of pancreatic beta cell dysfunction as non-obese Japanese subjects.
\end{abstract}

Key words: Obesity, Japanese, Beta cell function

DECREASED insulin secretion and decreased insulin sensitivity are both involved in the development of type 2 diabetes mellitus, but the proportion of their involvement is reported to be different from patient to patient $[1,2]$.

It was long described that Japanese patients with type 2 diabetes mellitus were often lean compared to Caucasians [3] and had predominantly impaired insulin secretory capacity [4-6]. On the other hand, recent reports suggest that type 2 diabetes mellitus accompanied by obesity has become common in Japan [7]. Obesity is associated with decreased insulin sensitivity [8]. Insulin resistance, therefore, is recognized as an important pathogenesis in these obese patients with diabetes mellitus or glucose intolerance [5]. However, to date, little is known about to what extent insulin secretory capacity is decreased in these obese patients

Submitted Feb. 1, 2013; Accepted Feb. 20, 2013 as EJ13-0046 Released online in J-STAGE as advance publication Mar. 16, 2013

Correspondence to: Hideaki Kaneto, M.D., Ph.D., Department of Metabolic Medicine, Osaka University Graduate School of Medicine, 2-2 Yamadaoka, Suita 565-0871, Osaka, Japan.

E-mail: kaneto@endmet.med.osaka-u.ac.jp compared to those who are lean and have similarly impaired glucose tolerance in a Japanese population.

The aim of the current study was to investigate whether obese subjects have different insulin secretory capacity compared to lean subjects with the same glucose tolerance in a Japanese population.

\section{Materials and Methods}

We used a database of the Amagasaki Visceral Fat Study, registered as UMIN000002391. The study was approved by the human ethics committee of Osaka University. Written informed consent was obtained from every participant. In the current study, a total of 1749 Japanese employees of the city office of Amagasaki, Hyogo, who underwent 75 -g oral glucose tolerance test (OGTT), were included. None of the subjects had anti-diabetic treatment. Exclusion criteria were as follows: under treatment of renal or hepatic diseases, malignant neoplasms, estimated glomerular filtration rate $(\mathrm{eGFR})<30 \mathrm{~mL} / \mathrm{min} / 1.73 \mathrm{~m}^{2}$, transaminase $\geq 200 \mathrm{IU} / \mathrm{L}$, blood pressure $\geq 180 / 110 \mathrm{mmHg}$, and triglycerides $\geq 1000 \mathrm{mg} / \mathrm{dL}$. Under 75 -g OGTT, 
plasma glucose and insulin levels were measured at $0,30,60$, and $120 \mathrm{~min}$, from which indices of insulin sensitivity and insulin secretion were calculated. The assessment of glucose tolerance was in accordance with the report of World Health Organization (WHO) and International Diabetes Foundation (IDF), using 110 and $126 \mathrm{mg} / \mathrm{dL}$ of fasting glucose levels and 140 and $200 \mathrm{mg} / \mathrm{dL}$ of 120-min glucose levels as cutoff points [9]: diabetes mellitus (fasting glucose $\geq 126 \mathrm{mg} / \mathrm{dL}$ or 120 -min glucose $\geq 126 \mathrm{mg} / \mathrm{dL}$ ), impaired glucose tolerance (fasting glucose $<126 \mathrm{mg} / \mathrm{dL}$ and 120-min glucose $\geq 140 \mathrm{mg} / \mathrm{dL}$ and $<200 \mathrm{mg} / \mathrm{dL}$ ), impaired fasting glucose (fasting glucose $\geq 110 \mathrm{mg} / \mathrm{dL}$ and $<126 \mathrm{mg} / \mathrm{dL}$ and 120-min glucose $<140 \mathrm{mg} / \mathrm{dL}$ ), and normal glucose tolerance (fasting glucose $<110 \mathrm{mg} / \mathrm{dL}$ and 120 $\min$ glucose $<140 \mathrm{mg} / \mathrm{dL}$ ). We also used $100 \mathrm{mg} / \mathrm{dL}$ of fasting glucose levels as another cutoff point, since 100 to $109 \mathrm{mg} / \mathrm{dL}$ of fasting glucose levels were recently proposed as "high-normal" range [10].

The primary outcome measure in the current study was pancreatic beta cell function evaluated with disposition index [11]. Insulin sensitivity was estimated with Matsuda index [12], in which mean plasma glucose and insulin concentrations during OGTT were calculated by the trapezoid method. Insulin response was evaluated by insulinogenic index [13], which was calculated as the ratio of the increase of insulin levels to that of glucose levels during the first 30 minutes of OGTT. Disposition index was calculated from the product of insulinogenic index and Matsuda index [11].

The study population was divided into two groups according to body mass index (BMI): non-obese subjects $\left(\mathrm{BMI}<25 \mathrm{~kg} / \mathrm{m}^{2}\right)$ and obese subjects (BMI $\geq 25$ $\left.\mathrm{kg} / \mathrm{m}^{2}\right)[14,15]$. We also evaluated visceral adiposity with waist circumference. Increased waist circumference was determined when their waist circumference was $85 \mathrm{~cm}$ or larger in males and $90 \mathrm{~cm}$ or larger in females $[15,16]$.

To assess beta cell function in different degrees of glucose tolerance, we classified the study population into the deciles of 120-min glucose levels. Disposition index, as well as Matsuda index and insulinogenic index, in each decile was thereafter compared between the obese and non-obese subjects. The difference was also assessed between the subjects with and without increased waist circumference.

Data are given as means and standard deviations (SD) for continuous variables or as percentages for discrete variables, if not otherwise mentioned. Since the distri- butions of Matsuda index, insulinogenic index, and disposition index were right-skewed, these indices were log-transformed. Differences of continuous variables between two groups were evaluated by the unpaired $t$ test. Dichotomous variables and other discrete variables between two groups were compared by the Fisher's exact test and by the chi square test, respectively, except for the ordinal categories of fasting and 120-min glucose levels, which were compared by the Mann-Whitney's $U$ test. We also performed logistic regression analysis to evaluate the association of obesity and visceral adiposity with decreased beta cell function. The decreased beta cell function was defined as the lowest quintile of disposition index in the whole study population. A $p$ value less than 0.05 was considered to be significant. Statistical analyses were performed using IBM SPSS Statistics Version 19 (SPSS Inc.).

\section{Results}

Table 1 shows the clinical characteristics of the study population. The study population was $50 \pm 9$ years old and 1487 subjects $(85 \%)$ were male. BMI was $22.7 \pm$ $1.7 \mathrm{~kg} / \mathrm{m}^{2}$ in non-obese subjects and $27.5 \pm 2.4 \mathrm{~kg} / \mathrm{m}^{2}$ in obese subjects. Compared to non-obese subjects, obese subjects were slightly but significantly younger $(49 \pm 10$ years old $v s .51 \pm 8$ years old: $p<0.01$ ) and more likely to have hyperglycemia and hyperinsulinemia (see Table 1).

They also had a significantly higher prevalence of hypertension and dyslipidemia (both $p<0.01$ ).

Fig. 1 shows the association of obesity with insulin sensitivity, insulin response, and beta cell function in each decile of 120-min glucose levels. The sample number and the fasting glucose levels in the subjects with and without obesity in each of the decile are shown in Table 2. Fig. 1A shows insulin sensitivity assessed with Matsuda index in non-obese and obese subjects. In both of the subjects, increased 120-min glucose levels during 75-g OGTT were associated with decreased values of Matsuda index (Pearson's correlation coefficient $r=-0.36, p<0.01$ ). When the index was compared between non-obese and obese subjects, obese subjects had significantly lower values of Matsuda index than non-obese subjects in every decile of 120-min glucose level (all $p<0.05$ ).

Fig. 1B shows insulin response assessed with insulinogenic index in non-obese and obese subjects. Increased 120-min glucose levels were associated with decreased values of insulinogenic index $(r=-0.43, p<$ 
Table 1 Clinical characteristics of the study population

\begin{tabular}{|c|c|c|c|}
\hline & Non-obese subjects $(n=870)$ & Obese subjects $(n=879)$ & $p$ value \\
\hline Age (year) & $51 \pm 8$ & $49 \pm 10$ & $<0.01$ \\
\hline Male & $731(84)$ & $756(86)$ & 0.26 \\
\hline Body mass index $\left(\mathrm{kg} / \mathrm{m}^{2}\right)$ & $22.7 \pm 1.7$ & $27.5 \pm 2.4$ & $<0.01$ \\
\hline \multicolumn{4}{|l|}{ Waist circumference $(\mathrm{cm})$ : } \\
\hline Male & $79 \pm 8$ & $93 \pm 7$ & $<0.01$ \\
\hline Female & $83 \pm 6$ & $92 \pm 6$ & $<0.01$ \\
\hline \multicolumn{4}{|l|}{ Glucose during 75-g OGTT (mg/dL) } \\
\hline 0 min & $97 \pm 14$ & $98 \pm 13$ & 0.15 \\
\hline $30 \mathrm{~min}$ & $161 \pm 37$ & $163 \pm 36$ & 0.33 \\
\hline $60 \mathrm{~min}$ & $157 \pm 56$ & $165 \pm 54$ & 0.01 \\
\hline $120 \mathrm{~min}$ & $122 \pm 45$ & $129 \pm 47$ & $<0.01$ \\
\hline \multicolumn{4}{|l|}{ Insulin during 75-g OGTT $(\mu \mathrm{U} / \mathrm{mL})$} \\
\hline $0 \mathrm{~min}$ & $5 \pm 3$ & $8 \pm 5$ & $<0.01$ \\
\hline $30 \mathrm{~min}$ & $28 \pm 19$ & $40 \pm 26$ & $<0.01$ \\
\hline $60 \mathrm{~min}$ & $33 \pm 22$ & $48 \pm 33$ & $<0.01$ \\
\hline $120 \mathrm{~min}$ & $27 \pm 23$ & $42 \pm 31$ & $<0.01$ \\
\hline OGTT-assessed glucose tolerance & & & $<0.01$ \\
\hline Normal glucose tolerance & $534(61)$ & $461(52)$ & \\
\hline Impaired fasting glucose & $136(16)$ & $154(18)$ & \\
\hline Impaired glucose tolerance & $129(15)$ & $187(21)$ & \\
\hline Diabetes mellitus & $71(8)$ & $77(9)$ & \\
\hline Fasting glucose & & & 0.04 \\
\hline$<100 \mathrm{mg} / \mathrm{dL}$ & $591(68)$ & $555(63)$ & \\
\hline 100 to $109 \mathrm{mg} / \mathrm{dL}$ & $158(18)$ & $179(20)$ & \\
\hline 110 to $125 \mathrm{mg} / \mathrm{dL}$ & $88(10)$ & $113(13)$ & \\
\hline$\geq 126 \mathrm{mg} / \mathrm{dL}$ & $33(4)$ & $32(4)$ & \\
\hline 120 -min glucose during 75 -g OGTT & & & $<0.01$ \\
\hline$<140 \mathrm{mg} / \mathrm{dL}$ & $674(77)$ & $616(70)$ & \\
\hline 140 to $199 \mathrm{mg} / \mathrm{dL}$ & $135(16)$ & $190(22)$ & \\
\hline$\geq 200 \mathrm{mg} / \mathrm{dL}$ & $61(7)$ & $73(8)$ & \\
\hline Hypertension & $273(31)$ & $355(40)$ & $<0.01$ \\
\hline Dyslipidemia & $469(54)$ & $572(65)$ & $<0.01$ \\
\hline Family history of diabetes mellitus & $106(12)$ & $133(15)$ & 0.08 \\
\hline
\end{tabular}

0.01 ). In every decile of 120 -min glucose levels, obese subjects had significantly higher values of insulinogenic index than non-obese subjects (all $p<0.05$ ).

Fig. $1 \mathrm{C}$ shows beta cell function assessed with disposition index in non-obese and obese subjects. In both subjects, 120-min glucose levels were negatively associated with the values of disposition index $(r=-0.62, p$ $<0.01$ ), as with the values of insulinogenic index. On the other hand, disposition index was not significantly different between non-obese and obese subjects in any decile of 120-min glucose levels (all $p>0.05$ ), which was in contrast to insulinogenic index.

Similar findings were observed when the subjects were divided according to waist circumference (Fig. 2). The sample number and the fasting glucose levels in the subjects with and without increased waist circumference in each decile of 120-min glucose levels are shown in Table 3. There was no significant difference in disposition index between the subjects with and without increased waist circumference (all $p>0.05$ ) (Fig. 2C). On the other hand, those with increased waist circumference had lower levels of Matsuda index and higher levels of insulinogenic index, although insulinogenic index in the highest decile exceptionally lost statistical significance ( $p=0.15$ ) (Fig. 2A and B).

We finally performed logistic regression analysis and investigated the association of obesity and increased waist circumference with decreased beta cell function (Table 4). As shown in Table 4, there was no significant association of obesity or increased waist circumference with decreased beta cell function. The similar findings were observed even when the subjects were limited to those with fasting glucose levels $<110 \mathrm{mg} /$ $\mathrm{dL}$ or $<100 \mathrm{mg} / \mathrm{dL}$ (Table 4 ). 

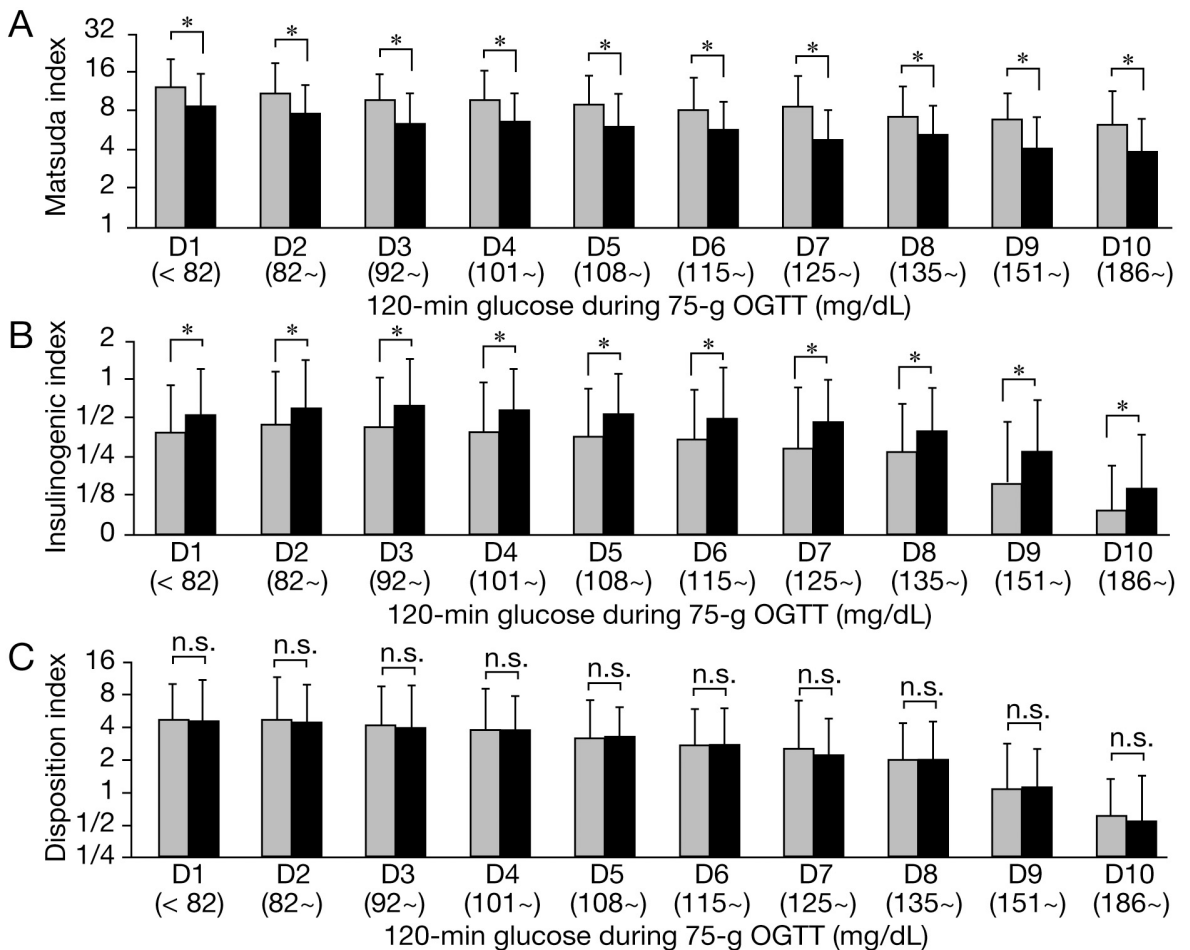

Fig. 1 Association of obesity with insulin secretory capacity and sensitivity in various degrees of glucose tolerance

Matsuda index (A), insulinogenic index (B) and disposition index (C) in each decile of 120-min glucose levels during 75-g OGTT (from D1 to D10) were compared between non-obese (shaded bars) and obese (filled bars) Japanese subjects. Asterisks mean statistically significant differences $(p<0.05)$, whereas "n.s." indicates no significance.

Table 2 Obesity and fasting glucose levels in each decile of 120-min glucose levels during 75-g OGTT

\begin{tabular}{|c|c|c|c|c|c|c|c|c|c|c|}
\hline \multirow{2}{*}{$\begin{array}{l}\text { Deciles of 120-min } \\
\text { glucose }(\mathrm{mg} / \mathrm{dL})\end{array}$} & \multicolumn{5}{|c|}{$\begin{array}{c}\text { Non-obese subjects }\left(\mathrm{BMI}<25 \mathrm{~kg} / \mathrm{m}^{2}\right) \\
\text { Fasting glucose }(\mathrm{mg} / \mathrm{dL})\end{array}$} & \multicolumn{5}{|c|}{$\begin{array}{l}\text { Obese subjects }\left(\mathrm{BMI} \geq 25 \mathrm{~kg} / \mathrm{m}^{2}\right) \\
\text { Fasting glucose }(\mathrm{mg} / \mathrm{dL})\end{array}$} \\
\hline & $<100$ & $100 \sim 109$ & $109 \sim 125$ & $126 \sim$ & Total & $<100$ & $100 \sim 109$ & $109 \sim 125$ & $126 \sim$ & Total \\
\hline $\mathrm{D} 1(<82)$ & $99(95)$ & $5(5)$ & $0(0)$ & $0(0)$ & $104(100)$ & $62(85)$ & $9(12)$ & $2(3)$ & $0(0)$ & $73(100)$ \\
\hline D2 (82 ) & $78(82)$ & $14(15)$ & $3(3)$ & $0(0)$ & $95(100)$ & $66(83)$ & $13(16)$ & $1(1)$ & $0(0)$ & $80(100)$ \\
\hline D3 (92 ) & $80(80)$ & 19 (19) & $1(1)$ & $0(0)$ & $100(100)$ & $59(75)$ & $16(20)$ & $4(5)$ & $0(0)$ & 79 (100) \\
\hline D3 (101 ) & $72(78)$ & $14(15)$ & $5(5)$ & $1(1)$ & $92(100)$ & $66(84)$ & $9(11)$ & $4(5)$ & $0(0)$ & 79 (100) \\
\hline D4 (108 ) & $62(73)$ & $17(20)$ & $6(7)$ & $0(0)$ & $85(100)$ & $60(72)$ & $17(20)$ & $6(7)$ & $0(0)$ & $83(100)$ \\
\hline D5 (115 ) & $74(78)$ & $13(14)$ & $6(6)$ & $2(2)$ & $95(100)$ & $70(78)$ & $18(20)$ & $2(2)$ & $0(0)$ & $90(100)$ \\
\hline D7 (125 ) & $49(67)$ & $16(22)$ & $7(10)$ & $1(1)$ & $73(100)$ & $61(62)$ & 27 (27) & $10(10)$ & $1(1)$ & 99 (100) \\
\hline D8 (135 ) & $36(51)$ & $22(31)$ & 12 (17) & $0(0)$ & $70(100)$ & $61(60)$ & $24(24)$ & $16(16)$ & $1(1)$ & $102(100)$ \\
\hline D9 (151 ) & $30(39)$ & $26(34)$ & $15(20)$ & $5(7)$ & $76(100)$ & $42(42)$ & $30(30)$ & $24(24)$ & $2(2)$ & 99 (100) \\
\hline D10 (186 ) & $11(14)$ & $12(15)$ & $33(41)$ & $24(30)$ & $80(100)$ & $7(7)$ & $16(17)$ & $44(46)$ & $28(29)$ & $95(100)$ \\
\hline
\end{tabular}

Data are $n$ (percentage).

Table 3 Visceral adiposity and fasting glucose levels in each decile of 120-min glucose levels during 75-g OGTT

\begin{tabular}{|c|c|c|c|c|c|c|c|c|c|c|}
\hline \multirow{2}{*}{$\begin{array}{l}\text { Deciles of } 120-\mathrm{min} \\
\text { glucose }(\mathrm{mg} / \mathrm{dL})\end{array}$} & \multicolumn{5}{|c|}{$\begin{array}{c}\text { Subjects without increased waist circumference } \\
\text { Fasting glucose }(\mathrm{mg} / \mathrm{dL})\end{array}$} & \multicolumn{5}{|c|}{$\begin{array}{l}\text { Subjects with increased waist circumference } \\
\text { Fasting glucose }(\mathrm{mg} / \mathrm{dL})\end{array}$} \\
\hline & $<100$ & $100 \sim 109$ & $109 \sim 125$ & $126 \sim$ & Total & $<100$ & $100 \sim 109$ & $109 \sim 125$ & $126 \sim$ & Total \\
\hline $\mathrm{D} 1(<82)$ & $71(95)$ & $4(5)$ & $0(0)$ & $0(0)$ & $75(100)$ & $90(88)$ & $10(10)$ & $2(2)$ & $0(0)$ & $102(100)$ \\
\hline D2 (82 ) & $53(78)$ & $12(18)$ & $3(4)$ & $0(0)$ & $68(100)$ & $91(85)$ & $15(14)$ & $1(1)$ & $0(0)$ & $107(100)$ \\
\hline D3 (92 ) & $47(75)$ & $15(24)$ & $1(2)$ & $0(0)$ & $63(100)$ & $92(79)$ & $20(17)$ & $4(3)$ & $0(0)$ & $116(100)$ \\
\hline D3 (101 ) & $47(82)$ & $6(11)$ & $4(7)$ & $0(0)$ & $57(100)$ & $91(80)$ & $17(15)$ & $5(4)$ & $1(1)$ & $114(100)$ \\
\hline D4 (108 ) & $32(62)$ & $13(25)$ & $7(13)$ & $0(0)$ & $52(100)$ & $90(78)$ & $21(18)$ & $5(4)$ & $0(0)$ & $116(100)$ \\
\hline D5 (115 ) & $51(80)$ & $8(13)$ & $4(6)$ & $1(2)$ & $64(100)$ & 93 (77) & 23 (19) & $4(3)$ & $1(1)$ & $121(100)$ \\
\hline D7 (125 ) & $29(58)$ & $13(26)$ & 7 (14) & $1(2)$ & $50(100)$ & $81(66)$ & $30(25)$ & $10(8)$ & $1(1)$ & $122(100)$ \\
\hline D8 (135 ) & $22(42)$ & 19 (37) & $10(20)$ & $0(0)$ & $51(100)$ & $75(62)$ & $27(22)$ & $18(15)$ & $1(1)$ & $121(100)$ \\
\hline D9 (151 ) & $18(35)$ & $21(40)$ & $11(21)$ & $2(4)$ & $52(100)$ & $55(45)$ & $35(28)$ & $28(23)$ & $5(4)$ & $123(100)$ \\
\hline D10 (186 ) & $5(8)$ & $12(18)$ & $29(45)$ & $19(29)$ & $65(100)$ & $13(12)$ & $16(15)$ & $48(44)$ & $33(30)$ & $110(100)$ \\
\hline
\end{tabular}

Data are $n$ (percentage). 

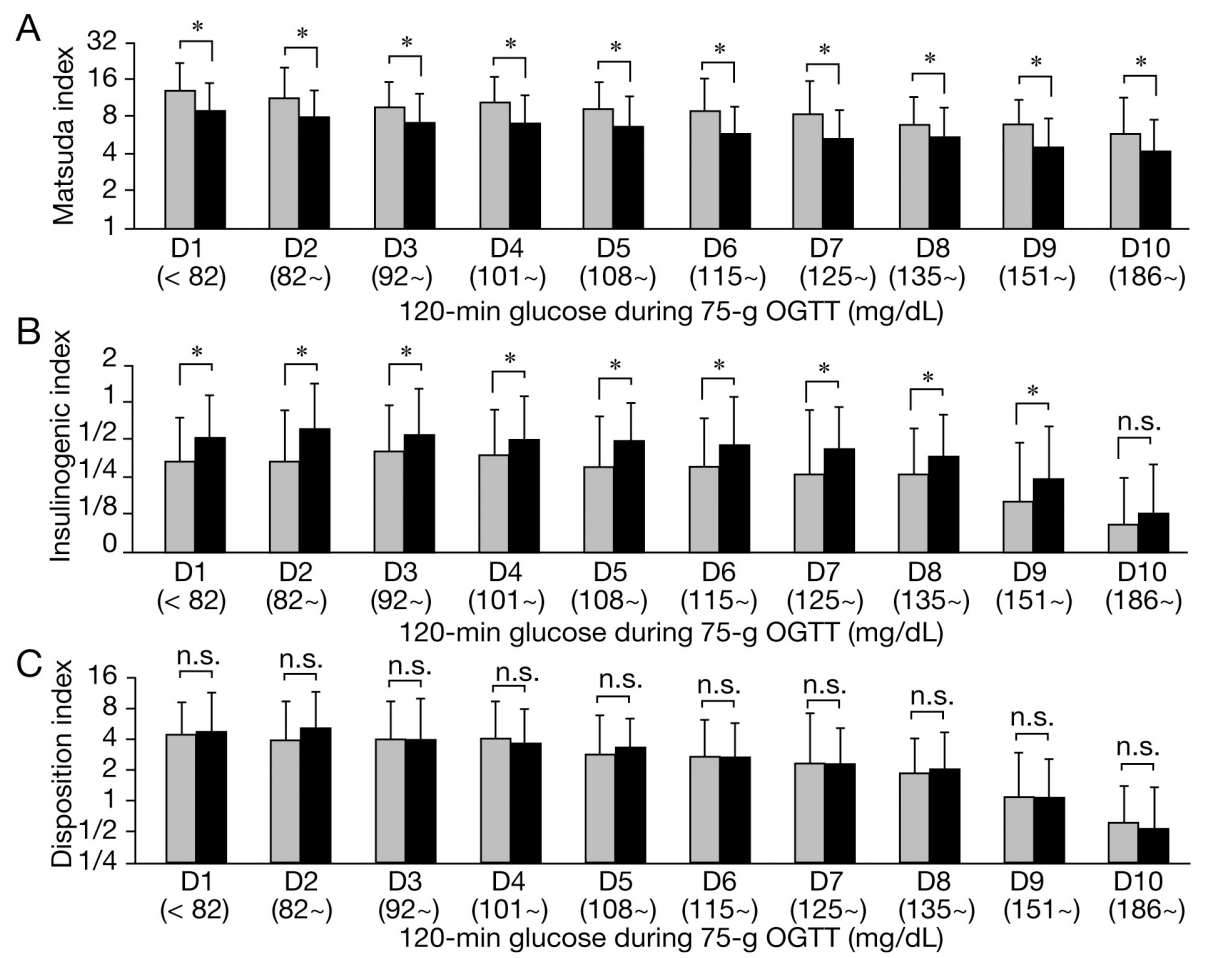

Fig. 2 Association of visceral adiposity with insulin secretory capacity and sensitivity in various degrees of glucose tolerance

Matsuda index (A), insulinogenic index (B) and disposition index (C) in each decile of 120-min glucose levels during 75-g OGTT (from D1 to D10) were compared between the Japanese subjects with (shaded bars) and without (filled bars) increased waist circumference ( $\geq 85 \mathrm{~cm}$ in males and $\geq 90 \mathrm{~cm}$ in females). Asterisks mean statistically significant differences $(p<0.05)$, whereas "n.s." indicates no significance.

Table 4 Association of obesity and increased waist circumference with decreased beta cell function

\begin{tabular}{|c|c|c|c|c|}
\hline & $\begin{array}{l}\text { Unadjusted OR } \\
\text { (Univariate model) }\end{array}$ & $\begin{array}{c}\text { Adjusted OR } \\
\text { (Multivariate model 1) }\end{array}$ & $\begin{array}{c}\text { Adjusted OR } \\
\text { (Multivariate model 2) }\end{array}$ & $\begin{array}{c}\text { Adjusted OR } \\
\text { (Multivariate model 3) }\end{array}$ \\
\hline \multicolumn{5}{|l|}{ Overall population $(n=1748)$} \\
\hline Non-obese without increased waist circumference & 1.0 (Reference) & 1.0 (Reference) & 1.0 (Reference) & 1.0 (Reference) \\
\hline Non-obese with increased waist circumference & $\begin{array}{c}1.1[0.8,1.6] \\
(p=0.55)\end{array}$ & $\begin{array}{l}1.2[0.8,1.9] \\
(p=0.32)\end{array}$ & $\begin{array}{l}1.1[0.7,1.6] \\
(p=0.78)\end{array}$ & $\begin{array}{l}1.1[0.7,1.7] \\
(p=0.76)\end{array}$ \\
\hline Obese without increased waist circumference & $\begin{array}{c}1.5[0.9,2.6] \\
(p=0.14)\end{array}$ & $\begin{array}{c}1.1[0.5,2.2] \\
(p=0.82)\end{array}$ & $\begin{array}{c}1.2[0.6,2.5] \\
(p=0.55)\end{array}$ & $\begin{array}{c}1.2[0.6,2.5] \\
(p=0.55)\end{array}$ \\
\hline Obese with increased waist circumference & $\begin{array}{c}1.2[0.9,1.6] \\
(p=0.19)\end{array}$ & $\begin{array}{c}1.0[0.7,1.5] \\
(p=0.91)\end{array}$ & $\begin{array}{c}1.0[0.7,1.4] \\
(p=0.80)\end{array}$ & $\begin{array}{c}1.0[0.7,1.4] \\
(p=0.83)\end{array}$ \\
\hline \multicolumn{5}{|c|}{ Subjects with fasting glucose $<110 \mathrm{mg} / \mathrm{dL}(n=1483)$} \\
\hline Non-obese without increased waist circumference & 1.0 (Reference) & 1.0 (Reference) & 1.0 (Reference) & 1.0 (Reference) \\
\hline Non-obese with increased waist circumference & $\begin{array}{l}1.3[0.8,2.0] \\
(p=0.27)\end{array}$ & $\begin{array}{l}1.2[0.7,2.0] \\
(p=0.42)\end{array}$ & $\begin{array}{l}1.1[0.6,1.8] \\
(p=0.84)\end{array}$ & $\begin{array}{l}1.1[0.6,1.8] \\
(p=0.78)\end{array}$ \\
\hline Obese without increased waist circumference & $\begin{array}{l}1.9[1.0,3.9] \\
(p=0.07)\end{array}$ & $\begin{array}{l}1.4[0.6,3.1] \\
(p=0.42)\end{array}$ & $\begin{array}{c}1.5[0.7,3.4] \\
(p=0.34)\end{array}$ & $\begin{array}{c}1.5[0.7,3.4] \\
(p=0.32)\end{array}$ \\
\hline Obese with increased waist circumference & $\begin{array}{c}1.2[0.8,1.8] \\
(p=0.27)\end{array}$ & $\begin{array}{c}1.0[0.7,1.6] \\
(p=0.88)\end{array}$ & $\begin{array}{c}0.9[0.6,1.5] \\
(p=0.80)\end{array}$ & $\begin{array}{c}1.0[0.6,1.5] \\
(p=0.92)\end{array}$ \\
\hline \multicolumn{5}{|l|}{ Subjects with fasting glucose $<100 \mathrm{mg} / \mathrm{dL}(n=1146)$} \\
\hline Non-obese without increased waist circumference & 1.0 (Reference) & 1.0 (Reference) & 1.0 (Reference) & 1.0 (Reference) \\
\hline Non-obese with increased waist circumference & $\begin{array}{l}1.5[0.8,2.8] \\
(p=0.22)\end{array}$ & $\begin{array}{l}1.2[0.6,2.4] \\
(p=0.55)\end{array}$ & $\begin{array}{l}1.1[0.6,2.2] \\
(p=0.77)\end{array}$ & $\begin{array}{l}1.2[0.6,2.3] \\
(p=0.68)\end{array}$ \\
\hline Obese without increased waist circumference & $\begin{array}{l}1.3[0.4,4.5] \\
(p=0.70)\end{array}$ & $\begin{array}{l}1.2[0.3,4.6] \\
(p=0.75)\end{array}$ & $\begin{array}{c}1.3[0.3,4.9] \\
(p=0.70)\end{array}$ & $\begin{array}{c}1.3[0.3,4.8] \\
(p=0.73)\end{array}$ \\
\hline Obese with increased waist circumference & $\begin{array}{l}1.3[0.7,2.2] \\
(p=0.43)\end{array}$ & $\begin{array}{c}0.9[0.5,1.7] \\
(p=0.76)\end{array}$ & $\begin{array}{l}0.9[0.5,1.6] \\
(p=0.65)\end{array}$ & $\begin{array}{l}0.9[0.5,1.7] \\
(p=0.72)\end{array}$ \\
\hline
\end{tabular}

Data are odds ratios (OR) and their 95\% confidence intervals for decreased beta cell function, relative to non-obese subjects without increased waist circumference.

Multivariate model 1: adjusted for 120-min glucose level. Multivariate model 2: adjusted for 120-min glucose level, age, and sex. Multivariate model 3: adjusted for 120-min glucose level, age, sex, hypertension, dyslipidemia, and family history of diabetes mellitus. 


\section{Discussion}

The current study revealed that disposition index derived from the data of 75-g OGTT was similarly decreased in obese Japanese subjects compared to nonobese Japanese subjects with the same post-load glucose levels. Similar findings were observed even after the stratification of the study population by waist circumference instead of BMI. These findings indicate that glucose intolerance is accompanied by a certain degree of pancreatic beta cell dysfunction in a Japanese population regardless of their obesity and visceral adiposity.

It has been well known that impaired beta cell function is a key pathogenesis for glucose intolerance, as decreased insulin sensitivity is $[1,2]$. However, it remains obscure whether there is any difference in beta cell dysfunction between obese and lean Japanese subjects. It has been thought that obese patients are accompanied by insulin resistance, and accordingly, decreased insulin secretion might have a less impact on glucose intolerance in obese patients than in lean patients. To the best of our knowledge, this is the first report comparing pancreatic beta cell function between Japanese subjects with and without obesity or visceral adiposity who have the same degree of glucose tolerance.

In the current study, obesity, i.e., BMI $\geq 25 \mathrm{~kg} / \mathrm{m}^{2}$, and visceral adiposity, i.e., waist circumference $\geq 85$ $\mathrm{cm}$ in males and $\geq 90 \mathrm{~cm}$ in females, were associated with increased insulinogenic index (Fig. 1B and Fig. 2B), meaning that insulin was secreted in response to glucose increment more strongly in subjects with obesity and visceral adiposity. However, when disposition index was subsequently calculated, there was no significant difference between those with and without obesity or increased waist circumference (Fig. 1C and 2C). The absence of significant difference was also confirmed by subsequent logistic regression analysis (Table 4). On the other hand, insulin sensitivity, assessed with Matsuda index, was significantly impaired in the subjects with obesity or increased waist circumference (Fig $1 \mathrm{~A}$ and $2 \mathrm{~A}$ ), as previously reported [8].

It is well recognized that pancreatic beta cells respond to an increment in plasma glucose with an increment in plasma insulin, and this response is modulated by the degree of insulin sensitivity, with a hyperbolic relation [11]. Disposition index is based on this hyperbolic relation between insulin sensitivity and insulin secretion, and quantifies pancreatic beta cell function as the product of insulin sensitivity and insulin secretion [11].
The current findings suggest that pancreatic beta cell function is similarly impaired in obese Japanese subjects compared to non-obese Japanese subjects with the same degree of glucose intolerance. The increased values of insulinogenic index observed in obese patients could be interpreted as a mere compensation of beta cells to insulin resistance.

Some previous studies of other ethnicities also reported that there was no significant difference in beta cell function between obese and lean subjects [17], although others did not always present consistent findings $[18,19]$. However, in their analysis, BMI cutoff points for defining obesity were sometimes larger than $25 \mathrm{~kg} / \mathrm{m}^{2}$ (e.g., 27 and $30 \mathrm{~kg} / \mathrm{m}^{2}$ ), meaning that the lean groups included some overweight subjects with $\mathrm{BMI} \geq$ $25 \mathrm{~kg} / \mathrm{m}^{2}$ and that obese subjects were not compared to those who were really "lean." Their results therefore might be affected by these study designs. Furthermore, previous studies seldom mentioned visceral adiposity, another key feature which could modify glucose metabolism [20]. It is now well known that visceral adiposity is commonly found even in subjects with lower BMI $[15,21]$. Stratification by BMI alone might underestimate the influence of adiposity on pancreatic beta cell function. In addition, the difference of ethnicity might have some influence on the association of obesity with beta cell function $[20,22,23]$. It was therefore clinically important to assess the association of visceral adiposity, as well as obesity, with beta cell function in an ethnic group of interest.

The current study demonstrated that there was no significant difference in beta cell function between Japanese subjects with and without obesity or visceral adiposity. These findings suggest that a progressive decline of beta cell function is observed in the course of the development of glucose intolerance and finally diabetes mellitus, regardless of obesity and visceral adiposity, in a Japanese population. Future longitudinal studies will be needed to validate the current crosssectional findings.

The current study had some limitations. First, 75-g OGTT was performed in the health check-ups, rather than for a specified research purpose, and there were no predetermined criteria for undergoing 75-g OGTT. Consequently, the glucose tolerance of the study populations was widely distributed. However, this wide distribution in turn enabled us to assess the association between obesity and beta cell function, in the population with various degree of glucose tolerance. 
Second, the definition of obesity and visceral adiposity in the current study was based on BMI and waist circumference, respectively. Although both of them are widely used for the assessment of adiposity in clinical and healthcare practice, they have limited accuracy, especially when compared to the assessment by computed tomography, for instance. Third, the current study had a high prevalence of male sex and a few females were included. However, given that the findings were unchanged after adjustment for sex as well as other variables (Table 2), we believe the influence of sex on the findings would be small. Future studies with a sufficient number of females will be needed to validate the current findings. Fourth, a larger sample size might be needed, especially when respective analyses were performed in each decile of 120-min glucose levels. However, the current sample size could detect at least $\sim 0.6 \mathrm{SD}$ of differences with $80 \%$ of power in each of the decile. In addition, even when the study population was divided into quintiles to detect smaller differences (i.e., $\sim 0.4 \mathrm{SD}$ ), observed findings were unchanged; there was no significant difference in disposition index, whereas Matsuda index was significantly lower and insulinogenic index was significantly higher in the subjects with obesity or abdominal adiposity (data not shown). Future studies with a larger sample size will be needed if the detection of a much smaller difference in each decile is required. Fifth and lastly, glucose tolerance was assessed by 75-g OGTT and pancreatic beta cell function was eval- uated with disposition index derived from the data of 75-g OGTT. Although 75-g OGTT has been widely used for the assessment of insulin secretion and insulin sensitivity both in clinical practice and in clinical studies [24-26], the unified load of glucose regardless of clinical background might affect measurements and findings. Indeed, the relative dose of glucose load per body weight was different between lean and obese subjects. This difference might affect the current findings. Scientifically accurate assessment might be achieved when appropriate absolute doses of glucose is loaded on subjects in proportion to their body weight.

In conclusion, disposition index derived from the data of 75-g OGTT was similarly decreased in obese Japanese subjects compared to non-obese Japanese subjects with the same post-load glucose levels. Future studies will be needed to confirm whether the development of glucose intolerance in obese Japanese subjects is accompanied by the same degree of pancreatic beta cell dysfunction as non-obese Japanese subjects.

\section{Acknowledgements}

Mitsuyoshi Takahara is a Research Fellow of the Japan Society for the Promotion of Science.

\section{Appendix}

There are no conflicts of interests associated with this manuscript.

\section{References}

1. The Committee of Japan Diabetes Society on the diagnostic criteria of diabetes mellitus, Seino Y, Nanjo K, Tajima N, Kadowaki T, et al. (2010) Report of the Committee on the classification and diagnostic criteria of diabetes mellitus. J Diabetes Invest 1: 212-228.

2. Fukushima M, Usami M, Ikeda M, Nakai Y, Taniguchi A, et al. (2004) Insulin secretion and insulin sensitivity at different stages of glucose tolerance: a cross-sectional study of Japanese type 2 diabetes. Metabolism 53: 831835 .

3. Sone H, Ito H, Ohashi Y, Akanuma Y, Yamada N (2003) Obesity and type 2 diabetes in Japanese patients. Lancet 361: 85 .

4. Kosaka K, Kuzuya T, Hagura R, Yoshinaga H (1996) Insulin response to oral glucose load is consistently decreased in established non-insulin-dependent diabetes mellitus: the usefulness of decreased early insulin response as a predictor of non-insulin-dependent diabetes mellitus. Diabet Med 13: S109-119.

5. Tanaka Y, Atsumi Y, Matsuoka K, Onuma T, Kawamori $\mathrm{R}$ (2000) Interesting insulin response to oral glucose load in young Japanese subjects with impaired glucose tolerance. Diabetes Care 23: 710-712.

6. Seino Y (2004) Pathogenic mechanism of type 2 diabetes mellitus. J Japan Soc Intern Med 93: 1749-1760.

7. Kobayashi M, Yamazaki K, Hirao K, Oishi M, Kanatsuka A, et al. (2006) The status of diabetes control and antidiabetic drug therapy in Japan--a cross-sectional survey of 17,000 patients with diabetes mellitus (JDDM 1). Diabetes Res Clin Pract 73: 198-204.

8. Oka R, Yagi K, Sakurai M, Nakamura K, Nagasawa SY, et al. (2012) Impact of visceral adipose tissue and subcutaneous adipose tissue on insulin resistance in middle-aged Japanese. J Atheroscler Thromb 19: 814-822. 
9. World Health Organization and International Diabetes Foundation (2006) Definition and diagnosis of diabetes mellitus and intermediate hyperglycaemia: Report of a WHO/IDF consultation. the WHO Document Production Services, Geneva.

10. Kadowaki T, Haneda M, Tominaga M, Yamada N, Iwamoto Y, et al. (2008) Report of the Japan Diabetes Society's committee on the diagnostic criteria for diabetes mellitus and glucose metabolism disorder: A new category of fasting plasma glucose value: "high-normal." J Japan Diab Soc 51: 281-283 (In Japanese).

11. Ahren B, Pacini G (2004) Importance of quantifying insulin secretion in relation to insulin sensitivity to accurately assess beta cell function in clinical studies. Eur J Endocrinol 150: 97-104.

12. Matsuda M, DeFronzo RA (1999) Insulin sensitivity indices obtained from oral glucose tolerance testing: comparison with the euglycemic insulin clamp. Diabetes Care 22: 1462-1470.

13. Seltzer HS, Allen EW, Herron AL Jr., Brennan MT (1967) Insulin secretion in response to glycemic stimulus: relation of delayed initial release to carbohydrate intolerance in mild diabetes mellitus. $J$ Clin Invest 46: 323-335.

14. Japan Society for the Study of Obesity (2011) Definition and diagnostic criteria for obesity. J Japan Soc Study Obes 17 Suppl: 1-2 (in Japanese).

15. The Examination Committee of Criteria for 'Obesity Disease' in Japan (2002) New criteria for 'obesity disease' in Japan. Circ J 66: 987-992.

16. The Examination Committee of Criteria for the Metabolic Syndrome in Japan (2005) Definition and diagnostic criteria of the metabolic syndrome. J Japan Soc Intern Med 94: 794-809.

17. Gastaldelli A, Ferrannini E, Miyazaki Y, Matsuda M, DeFronzo RA (2004) Beta-cell dysfunction and glucose intolerance: results from the San Antonio metabolism (SAM) study. Diabetologia 47: 31-39.
18. Elbein SC, Wegner K, Kahn SE (2000) Reduced betacell compensation to the insulin resistance associated with obesity in members of caucasian familial type 2 diabetic kindreds. Diabetes Care 23: 221-227.

19. Bergman RN, Phillips LS, Cobelli C (1981) Physiologic evaluation of factors controlling glucose tolerance in man: measurement of insulin sensitivity and beta-cell glucose sensitivity from the response to intravenous glucose. J Clin Invest 68: 1456-1467.

20. Huxley R, James WP, Barzi F, Patel JV, Lear SA, et al. (2008) Ethnic comparisons of the cross-sectional relationships between measures of body size with diabetes and hypertension. Obes Rev 9 Suppl 1: 53-61.

21. Lean ME, Han TS, Morrison CE (1995) Waist circumference as a measure for indicating need for weight management. BMJ 311: 158-161.

22. Nakagami T, Qiao Q, Carstensen B, Nhr-Hansen C, Hu G, et al. (2003) Age, body mass index and Type 2 diabetes-associations modified by ethnicity. Diabetologia 46 : 1063-1070.

23. Chandler-Laney PC, Phadke RP, Granger WM, Munoz JA, Man CD, et al. (2010) Adiposity and beta-cell function: relationships differ with ethnicity and age. Obesity (Silver Spring) 18: 2086-2092.

24. Nakamura A, Terauchi Y (2013) Factors associated with the glucose-lowering effect of vildagliptin identified from the results of the oral glucose tolerance test in Japanese patients with type 2 diabetes. Endocr $J 60$ : 45-49.

25. Oka R, Yagi K, Sakurai M, Nakamura K, Moriuchi T, et al. (2012) Insulin secretion and insulin sensitivity on the oral glucose tolerance test (OGTT) in middle-aged Japanese. Endocr $J$ 59: 55-64.

26. Saisho Y, Miyakoshi K, Ikenoue S, Kasuga Y, Matsumoto T, et al. (2012) Marked decline in beta cell function during pregnancy leads to the development of glucose intolerance in Japanese women. Endocr $J$ 60: 533-539. 